The British Dental Association has warned that recent moves to ease the high levels of pandemic restrictions facing dental practices in England are unlikely to soften access problems, as new evidence from Healthwatch England highlights the ongoing crisis facing dental services, including the high numbers of children missing out on care.

According to a survey of high street dentists in England:

$\rightarrow$ Nearly a third of dentists (33\%) have said they have no intention of relaxing COVID-19 precautions, in line with new protocols issued by NHS England in November. Half say the arrival of the Omicron variant has had a high impact on their willingness to ease restrictions. Until the changes took effect, dentists have had to maintain gaps of up to an hour between most treatments, to reduce the risk of viral transmission, an approach that has radically reduced patient numbers.

$\rightarrow$ In light of wider winter pressures, and expected surge in other conditions like flu and the common cold $62 \%$ say the changes - which place patients on two pathways given risk of respiratory infection - will make little to no difference to the volumes of patients they can treat.

$\rightarrow$ Over $40 \%$ of dentists indicate they are now likely to change career or seek early retirement in the next 12 months given the current pressures on the service. Over half state they are likely to reduce their NHS commitment. 1 in 10 estimate their practices will close in the next 12 months.

$\rightarrow$ The Government's handling of NHS dentistry is having a devastating impact on morale. $72 \%$ state the lack of clarity over the government's controversial imposed activity targets - increased on 1 January 2022 - is having a high impact on their morale. $70 \%$ say the same given uncertainty over the direction of pledged reforms to the service.

$\rightarrow$ Nearly two thirds of practices (62\%) estimate they are continuing to operate under $70 \%$ of their pre-COVID capacity.

The BDA and Healthwatch both issue a joint message to Chancellor Rishi Sunak ahead of the budget to guarantee funding for the rebuild and recovery of services. At this time not a penny of the government's multi-billion pound catch-up programme has been allocated to primary care dentistry. Over 37 million NHS appointments have been lost since lockdown in England alone, over 11 million for children. Tooth decay has been long established as the number one reason for hospital admissions among young children.

While the government has pledged reform of NHS dentistry by April 2022, the BDA has consistently warned that steps must be taken to stem the flow of talent from the workforce, and to provide the necessary resources to underpin any new system. BDA Chair Eddie Crouch said: 'It is tragic that so many million children are missing out on dental care. The government has a duty to ensure this does not become the new normal.

'For the sake of families across England we need to see real ambition from Ministers. Pandemic restrictions have been eased, but the gains appear modest at best. Patients are still struggling to secure appointments, and a frustrated workforce is looking for the exit. The Government keeps saying NHS dentistry is a top priority, but not a penny of investment has been offered. These problems are being felt in every community, and require deeds, not words.'

\title{
Four BSPD members recognised with life membership
}

Four members of the British Society for Paediatric Dentistry have been awarded Honorary Life Membership of BSPD.

Richard Welbury, Barbara Chadwick, Stephen Fayle and Linda Arch have all played important leadership roles, both clinically and personally, serving in different capacities on BSPD's national executive.

Professor Richard Welbury CBE is a former President of BSPD as well as of the European Academy of Paediatric Dentistry. In 2015 he chaired the organising committee of the International Association of Paediatric Dentistry congress in Glasgow. He is internationally known for his textbook on paediatric dentistry.

Professor Barbara Chadwick MBE was, for most of her career, based at Cardiff University School of Dentistry, most recently as Director of Education and Students, where she inspired many young dentists to choose paediatric dentistry as a career pathway. A national spokesperson for BSPD, Stephen
Fayle has been a Consultant in Paediatric Dentistry and Honorary Senior Lecturer at Leeds Dental Institute (LDI) for most of his career. His influence has been felt throughout the UK due to his unstinting 25-year commitment to the wider NHS and national professional societies.

At the invitation of the Chief Dental Officer for England, Sara Hurley, he has led on the NHS Commissioning Standard for Specialist Paediatric Dentistry and he has been Chair of the Managed Clinical Network for Paediatric Dentistry in Yorkshire and Humber.

Linda Arch combined roles as a clinician, a researcher, a lecturer and a mentor. The contribution she made to the Merseyside branch was enormous, serving in most branch roles; at national level she served as a Secretary for BSPD. As a postgraduate tutor for Health Education England she ran courses in paediatric dentistry.

All four life memberships were announced at the 2021 annual conference hosted by

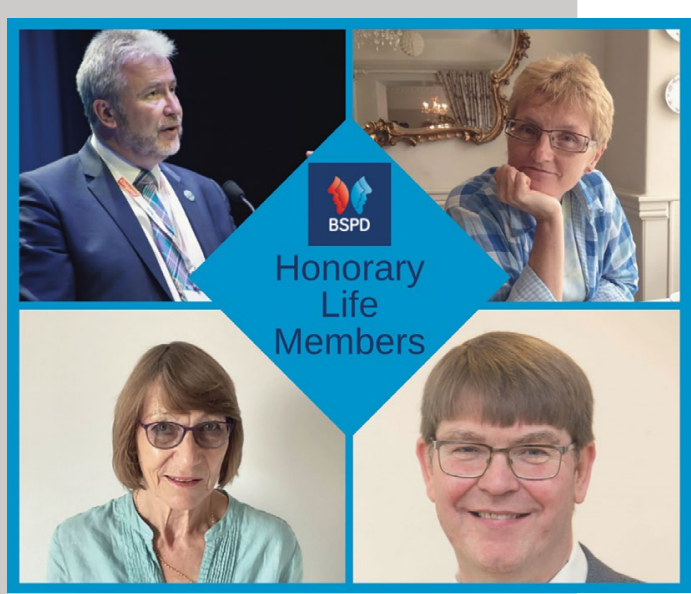

the Merseyside branch and are due to be presented at a study day in Liverpool in 2022.

BSPD spokesperson Professor Claire

Stevens CBE said: 'All four members have played an exceptional role in BSPD's story over the last three decades and we are very happy that they will all remain part of the Society to which they have given so much.' 